\title{
Serum levels of insulin-like growth factor system components and relationship to bone metabolism in Type 1 and Type 2 diabetes mellitus patients
}

\author{
P M Jehle ${ }^{1}$, D R Jehle ${ }^{1}$, S Mohan ${ }^{3}$ and B O Böhm² \\ ${ }^{1}$ Department of Internal Medicine II, Division of Nephrology, ${ }^{2}$ Department of Internal Medicine I, Division of Endocrinology, ${ }^{3}$ Mineral Metabolism (151), \\ Jerry L Pettis VA Medical Center, Loma Linda University, Loma Linda, California, USA \\ (Requests for offprints should be addressed to P M Jehle, Universität Ulm, Abteilung Innere Medizin II, Sektion Nephrologie, Robert-Koch-Straße 8, \\ 89081 Ulm, Germany)
}

\begin{abstract}
Osteopenia has been ascribed to diabetics without residual insulin secretion and high insulin requirement. However, it is not known if this is partially due to disturbances in the IGF system, which is a key regulator of bone cell function.

To address this question, we performed a cross-sectional study measuring serum levels of IGF-I, IGF-binding protein-1 (IGFBP-1), IGFBP-3, IGFBP-4 and IGFBP-5 by specific immunoassays in 52 adults with Type $1(n=27)$ and Type $2(n=25)$ diabetes mellitus and 100 age- and sex-matched healthy blood donors. In the diabetic patients, we further determined serum levels of proinsulin, intact parathyroid hormone (PTH), 25-hydroxyvitamin $\mathrm{D}_{3}, 1,25$-dihydroxyvitamin $\mathrm{D}_{3}$ and several biochemical bone markers, including osteocalcin (OSC), bone alkaline phosphatase (B-ALP), carboxy-terminal propeptide of type I procollagen (PICP), and type I collagen cross-linked carboxy-terminal telopeptide (ICTP). Urinary albumin excretion was ascertained as a marker of diabetic nephropathy. Bone mineral density (BMD) of hip and lumbar spine was determined by dual-energy X-ray absorptiometry. Data are presented as means \pm s.E.M. Differences between the experimental groups were determined by performing a one-way analysis of variance (ANOVA), followed by Newman-Keuls test. Correlations between variables were assessed using univariate linear regression analysis and partial correlation analysis.

Type 1 diabetics showed significantly lower IGF-I $(119 \pm 8 \mathrm{ng} / \mathrm{ml})$ and IGFBP-3 $(2590 \pm 104 \mathrm{ng} / \mathrm{ml})$ but higher IGFBP-1 levels $(38 \pm 10 \mathrm{ng} / \mathrm{ml})$ compared with Type 2 patients $(170 \pm 13,2910 \pm 118,11 \pm 3$ respectively; $P<0 \cdot 05)$ or healthy controls $(169 \pm 5,4620 \pm 192$, $3 \cdot 5 \pm 0.4$ respectively; $P<0 \cdot 01)$. IGFBP-5 levels were markedly lower in both diabetic groups (Type 1, $228 \pm 9$;
\end{abstract}

Type 2, $242 \pm 11 \mathrm{ng} / \mathrm{ml})$ than in controls $(460 \pm 7 \mathrm{ng} / \mathrm{ml}$, $P<0 \cdot 01$ ), whereas IGFBP-4 levels were similar in diabetics and controls. IGF-I correlated positively with IGFBP-3 and IGFBP-5 and negatively with IGFBP-1 and IGFBP-4 in all subjects. Type 1 patients showed a lower BMD of hip (83 $\pm 2 \%$, Z-score) and lumbar spine $(93 \pm 2 \%)$ than Type 2 diabetics $(93 \pm 5 \%, 101 \pm 5 \%$ respectively), reaching significance in the female subgroups $(P<0 \cdot 05)$. In Type 1 patients, BMD of hip correlated negatively with IGFBP-1 $(r=-0 \cdot 34, P<0 \cdot 05)$ and IGFBP-4 $(r=-0 \cdot 3, P<0 \cdot 05)$ but positively with IGFBP-5 $(r=0 \cdot 37, P<0 \cdot 05)$, which was independent of age, diabetes duration, height, weight and body mass index, as assessed by partial correlation analysis. Furthermore, biochemical markers indicating bone loss (ICTP) and increased bone turnover (PTH, OSC) correlated positively with IGFBP-1 and IGFBP-4 but negatively with IGF-I, IGFBP-3 and IGFBP-5, while the opposite was observed with bone formation markers (PICP, B-ALP) and vitamin $\mathrm{D}_{3}$ metabolites. In 20 Type 2 patients in whom immunoreactive proinsulin could be detected, significant positive correlations were found between proinsulin and BMD of hip $(r=0.63, P<0 \cdot 005)$, IGF-I $(r=0.59, P<0 \cdot 01)$ as well as IGFBP-3 $(r=0 \cdot 49, P<0 \cdot 05)$. Type 1 and Type 2 patients with macroalbuminuria showed a lower BMD of hip, lower IGFBP-5 but higher IGFBP-4 levels, suggesting that diabetic nephropathy may contribute to bone loss by a disturbed IGF system.

In conclusion, the findings of this study support the hypothesis that the imbalance between individual IGF system components and the lack of endogenous proinsulin may contribute to the lower BMD in Type 1 diabetics.

Journal of Endocrinology (1998) 159, 297-306

\section{Introduction}

Bone remodeling is regulated by systemic hormones and locally produced factors acting in concert to maintain bone mass. Insulin-like growth factor-I (IGF-I) is an important anabolic regulator of bone cell function (e.g. decreasing collagen degradation, increasing bone matrix deposition, and increasing osteoblastic cell recruitment; McCarthy 
et al. 1989, Mohan 1993). The effects of IGF-I are modulated by at least six different IGF-binding proteins (IGFBPs) and IGFBP proteases (Jones \& Clemmons 1995, Rajaram et al. 1997). The key role of the IGF system for bone formation is demonstrated by the finding that approximately $50 \%$ of basal bone cell proliferation can be blocked by inhibiting the actions of endogenously produced IGFs by bone cells in serum-free culture (Mohan et al. 1989, Mohan 1993). In bone cells, locally produced IGF system components (e.g. IGF-I) may act as potential endogenous mediators of parathyroid hormone (PTH) and calcitriol, and may modulate IGF actions both in a positive (e.g. IGFBP-5) and negative (e.g. IGFBP-4) manner (McCarthy et al. 1989, Mohan et al. 1989, Mohan 1993). Studies in patients with osteoporosis suggest that IGFBP-1 and IGFBP-4 are possible 'inhibitors' of IGF action, whereas IGFBP-3 may play a 'stimulatory' role (Rosen et al. 1992, Wüster et al. 1993).

A number of endocrine disorders, such as Type 1 diabetes mellitus, hypogonadism, hyperthyroidism, hyperparathyroidism and hypercorticism, may lead to osteopenia and osteoporosis. In juvenile-onset diabetics, a greater than $10 \%$ loss in forearm bone mass, characteristic of cortical bone, was measured in more than $50 \%$ of the subjects studied (Levin et al. 1976). Osteopenia has been ascribed to diabetics without residual insulin secretion and high insulin requirement (McNair et al. 1978), whereas a large population-based study reported an increased bone mineral density (BMD) in Type 2 diabetes (Van Daele et al. 1995). A long-term study investigating 16 Type 1 and 19 Type 2 patients over approximately 12 years (Krakauer et al. 1995) suggested that, in Type 1 patients, low bone formation retards bone accumulation during growth, metabolic effects of poor glycemic control lead to increased bone resorption and bone loss in young adults, and low bone turnover retards age-related bone loss.

There has been no study of the relationship between bone metabolism and circulating levels of IGF system components in the two types of diabetes. In Type 1 diabetics, decreased serum levels of IGF-I have been reported which are attributed to inadequate insulinization (Dills et al. 1995). Another study reported a diminished osteoblast function (Bouillon et al. 1995). In prepubertal Type 1 diabetics, it has been shown that the low circulating IGF-I levels contribute to impaired growth (Strasser-Vogel et al. 1995). Based on these findings, we proposed the hypothesis that bone metabolism in diabetic subjects may be influenced by circulating IGF system components and $\beta$-cell function. As a means of testing this hypothesis, we have measured, in a cross-sectional protocol, serum levels of IGF-I and IGFBPs-1, $-3,-4$ and -5 in patients with Type 1 and Type 2 diabetes and in nondiabetic control subjects. In addition, BMD of hip and lumbar spine, biochemical markers (Power \& Fottrell 1991, Eriksen et al. 1993) indicating bone formation (bone alkaline phosphatase (B-ALP) isoenzyme and procollagen carboxy-peptide (PICP)), bone turnover (osteocalcin; OSC), and bone resorption (type I collagen carboxyterminal telopeptide; ICTP), as well as serum levels of proinsulin, insulin and C-peptide, were determined and correlated to circulating levels of IGF system components. The findings of this study are consistent with a potential role of circulating IGF system components and $\beta$-cell function in regulating bone metabolism in diabetic patients.

\section{Subjects and Methods}

\section{Patients and study design}

In this cross-sectional study we investigated 52 diabetic patients (27 Type 1 and 25 Type 2) who were recruited from 65 diabetics who had been screened in the outpatient clinic of the University Hospital Ulm during a 6-month period. Patients with bone fractures during the last year, degenerative spondylosis, Paget's disease, metastatic bone lesions, immobilization, or other severe illnesses (e.g. liver, heart and kidney failure) were excluded from the study. The normal ranges of IGF-I and IGFBP levels were obtained from 100 age- and sex-matched healthy blood donors (mean age: $57 \pm 2.6$ years; female/male: 49/51) who were randomly recruited from the University Hospital Ulm. Patients' characteristics are summarized in Table 1. All subjects gave informed consent to participate in this study. Body mass index (BMI) was calculated as weight $(\mathrm{kg}) /$ height $^{2}\left(\mathrm{~m}^{2}\right)$. Six female Type 1 patients and twelve female Type 2 patients were postmenopausal (median 10 and 12 years). One woman with Type 1 diabetes was treated with sodium fluoride; one female Type 2 diabetic received transdermal estrogen. The other patients did not receive any drugs to prevent or treat osteoporosis. All Type 1 patients studied were C-peptide negative and were on intensified conventional insulin therapy with neutral protamin hagedorn $(\mathrm{NPH})$ insulin twice daily to cover their basal insulin requirements and regular insulin before meals three times per day. In the Type 2 group, seventeen patients (female/male: 9/8) injected insulin twice daily (NPH insulin/regular insulin: $70 \pm 10 \% / 30 \pm 8 \%$ ), two patients (female/male: 1/1) combined insulin (NPH insulin at bedtime) with glibenclamide in the morning, and six patients (female/male: 3/3) were treated with glibenclamide only.

\section{Assays}

All blood samples were non-fasting morning samples. Serum creatinine, calcium and phosphate were measured by standard biochemical methods. Haemoglobin A1c (HbA1c) was determined by HPLC to assess diabetes control (normal below 6.1\%). As a marker of diabetic nephropathy, albumin excretion was measured in 24-h 
Table 1 Clinical data and serum parameters of bone metabolism in Type 1 and Type 2 diabetes patients (mean values \pm S.E.M.)

\begin{tabular}{|c|c|c|c|}
\hline & $\begin{array}{l}\text { Type } 1 \\
(n=12 \mathrm{~F} / 15 \mathrm{M})\end{array}$ & $\begin{array}{l}\text { Type } 2 \\
(n=13 \mathrm{~F} / 12 \mathrm{M})\end{array}$ & $\begin{array}{l}\boldsymbol{P} \\
(\mathrm{ANOVA})\end{array}$ \\
\hline \multicolumn{4}{|l|}{ Clinical data } \\
\hline Age (years) & $48 \pm 4^{\S \S} / 54 \pm 3^{\#}$ & $60 \pm 2 / 64 \pm 2$ & ** \\
\hline BMI $\left(\mathrm{kg} / \mathrm{m}^{2}\right)$ & $22 \cdot 3 \pm 0 \cdot 5^{\S \S} / 24 \pm 0 \cdot 6$ & $28 \cdot 3 \pm 1 \cdot 4^{\$ \$} / 24 \cdot 5 \pm 0 \cdot 7$ & * \\
\hline Duration of diabetes (years) & $23 \pm 2 \cdot 3^{\S} / 20 \pm 3 \cdot 4$ & $14 \pm 2 \cdot 1 / 16 \pm 3 \cdot 5$ & * \\
\hline HbA1c (\%) & $8 \cdot 1 \pm 0 \cdot 4^{\S+} / 7 \cdot 4 \pm 0 \cdot 2$ & $9 \cdot 1 \pm 0 \cdot 4 / 8 \cdot 2 \pm 0 \cdot 4$ & * \\
\hline Injected insulin (IU/kg body weight) & $0 \cdot 55 \pm 0 \cdot 04 / 0 \cdot 57 \pm 0 \cdot 05$ & $0 \cdot 53 \pm 0 \cdot 06 / 0 \cdot 44 \pm 0 \cdot 07$ & \\
\hline Creatinine $(37-110 \mu \mathrm{mol} / \mathrm{l})$ & $84 \pm 6 / 90 \pm 4$ & $76 \pm 4 / 95 \pm 5$ & \\
\hline Excretion of albumin in urine $(\mu \mathrm{g} / \mathrm{min})$ & $221 \pm 177^{\S \S++} / 6 \cdot 3 \pm 2 \cdot 6^{\# \#}$ & $18 \pm 10^{\$ \$} / 341 \pm 145$ & ** \\
\hline \multicolumn{4}{|c|}{ Serum parameters of bone metabolism (reference values) } \\
\hline Calcium $(2 \cdot 0-2 \cdot 8 \mathrm{mmol} / \mathrm{l})$ & $2 \cdot 4 \pm 0 \cdot 03 / 2 \cdot 4 \pm 0 \cdot 02$ & $2 \cdot 4 \pm 0 \cdot 02 / 2 \cdot 4 \pm 0 \cdot 03$ & \\
\hline Phosphate $(0 \cdot 8-1.5 \mathrm{mmol} / \mathrm{l})$ & $1 \cdot 1 \pm 0 \cdot 06 / 1 \cdot 0 \pm 0 \cdot 05$ & $1 \cdot 1 \pm 0 \cdot 06 / 1 \cdot 0 \pm 0 \cdot 05$ & \\
\hline PTH (10-65 pg/ml) & $26 \pm 5 \cdot 5 / 16 \pm 3 \cdot 6^{\#}$ & $25 \pm 4 \cdot 7 / 43 \pm 3 \cdot 2$ & * \\
\hline $25-\mathrm{OHD}_{3}(16-74 \mathrm{ng} / \mathrm{ml})$ & $22 \cdot 2 \pm 3 \cdot 5 / 17 \cdot 6 \pm 2$ & $26 \cdot 1 \pm 3 \cdot 5 / 24 \cdot 2 \pm 3 \cdot 4$ & \\
\hline $1,25-(\mathrm{OH})_{2} \mathrm{D}_{3}(10-60 \mathrm{pg} / \mathrm{ml})$ & $45 \pm 4 / 54 \pm 5$ & $45 \pm 5 \cdot 3 / 40 \pm 2$ & \\
\hline $\begin{array}{l}\text { OSC (F: } 11-39 \mathrm{ng} / \mathrm{ml}) \\
(\mathrm{M}: 13-48 \mathrm{ng} / \mathrm{ml})\end{array}$ & $17 \cdot 5 \pm 1 \cdot 9 / 14 \cdot 6 \pm 1 \cdot 7$ & $14 \cdot 7 \pm 1 \cdot 8 / 13 \cdot 3 \pm 1 \cdot 2$ & \\
\hline $\begin{array}{c}\text { B-ALP (F: } 7 \cdot 5-15 \cdot 7 \mathrm{ng} / \mathrm{ml}) \\
(\mathrm{M}: 8-16.8 \mathrm{ng} / \mathrm{ml})\end{array}$ & $8 \cdot 4 \pm 0 \cdot 6 / 11 \cdot 7 \pm 1$ & $9 \cdot 8 \pm 1 \cdot 3 / 9 \cdot 6 \pm 1$ & \\
\hline $\begin{array}{l}\text { PICP (F: 50-170 ng/ml) } \\
(\mathrm{M}: 38-202 \mathrm{ng} / \mathrm{ml})\end{array}$ & $137 \pm 11 / 134 \pm 9$ & $115 \pm 9 / 109 \pm 10$ & \\
\hline $\begin{array}{c}\text { ICTP }(\mathrm{F:} 1 \cdot 8-5 \mathrm{ng} / \mathrm{ml}) \\
(\mathrm{M}: 1 \cdot 8-5 \mathrm{ng} / \mathrm{ml})\end{array}$ & $3 \cdot 9 \pm 0 \cdot 3 / 3 \cdot 9 \pm 0 \cdot 7$ & $3 \cdot 1 \pm 0 \cdot 2 / 4 \cdot 4 \pm 0 \cdot 5$ & \\
\hline PICP versus ICTP & $35 \cdot 1 / 34 \cdot 4^{\#}$ & $37 \cdot 1^{\$} / 24 \cdot 8$ & * \\
\hline
\end{tabular}

ANOVA: Type 1 vs Type $2:{ }^{*}=P<0 \cdot 05,{ }^{*}=P<0 \cdot 005 ;$ Newman-Keuls test: female Type 1 vs female Type $2: \S=P<0 \cdot 05, \S \S=P<0 \cdot 005 ;$ male Type 1 vs male Type 2: $\#=P<0 \cdot 05, \# \#=P<0 \cdot 005$; female Type 1 vs male Type $1:+=P<0 \cdot 05,++=P<0 \cdot 005 ;$ female Type 2 vs male Type $2: \$=P<0 \cdot 05 ; \$ \$=P<0 \cdot 005$. $\mathrm{M}$, male; F, female.

urine (Turbitimer; Behring, Marburg, Germany; normal below $20 \mu \mathrm{g} / \mathrm{min}$; microalbuminuria: $21-300 \mu \mathrm{g} / \mathrm{min}$; macroalbuminuria $>300 \mu \mathrm{g} / \mathrm{min}$ ). To correct for sampling errors, urine was examined on at least two occasions.

To assess bone metabolism we determined, by RIA: B-ALP (bone-specific alkaline phosphatase; Hybritech, Köln, Germany), OSC (osteocalcin; CIS, Dreieich, Germany), ICTP (type I collagen cross-linked carboxyterminal telopeptide; Pharmacia, Freiburg, Germany), and PICP (carboxy-terminal propeptide of type I procollagen; Pharmacia). 25-Hydroxyvitamin $\mathrm{D}_{3}\left(25-\mathrm{OHD}_{3}\right)$ and 1,25-dihydroxyvitamin $\mathrm{D}_{3}\left(1,25-(\mathrm{OH})_{2} \mathrm{D}_{3}\right)$ were measured by specific RIAs (Incstar, Stillwater, MN, USA) with a less than $2 \cdot 5 \%$ cross-reactivity to other vitamin D metabolites. Intact PTH was measured using a chemiluminescence immunometric assay (Nichols, California, CA, USA) with intra- and interassay coefficients of variation of less than $7 \%$.

The components of the IGF system were measured according to published protocols (Bang et al. 1994, Blum \& Breier 1994, Mohan et al. 1995a, Honda et al. 1996). IGF-I was determined by a IGFBP-blocked specific RIA (Mediagnost, Tübingen, Germany) with a cross-reactivity to IGF-II of less than $0.05 \%$ and intra- and interassay coefficients of variation of less than $4 \%$ and $8 \%$. As given by the manufacturer, the 5th, 50th, and 95th percentiles for healthy subjects aged 30-40 years $(n=82)$ were 109 , 188 and $324 \mathrm{ng} / \mathrm{ml}$; for ages $40-50$ years $(n=83): 103,178$ and $307 \mathrm{ng} / \mathrm{ml}$; for ages $50-60$ years $(n=61): 97,169$ and $294 \mathrm{ng} / \mathrm{ml}$; for ages 60-70 years $(n=32)$ : 91, 161 and $284 \mathrm{ng} / \mathrm{ml}$ respectively. IGFBP-3 was determined by a specific RIA with intra- and interassay coefficients of variation of less than $3.5 \%$ and $7 \cdot 5 . \%$, and no cross-reaction with IGFBP-1 or IGFBP-2 (Mediagnost). As given by the manufacturer, the 5th, 50th, and 95th percentiles for healthy subjects aged 30-40 years $(n=28)$ were 2080, 3180 and $4860 \mathrm{ng} / \mathrm{ml}$; for ages 40-50 years $(n=37)$ : 2010, 3080 and $4700 \mathrm{ng} / \mathrm{ml}$; for ages 50-60 years $(n=32): 1960,3020$ and $4650 \mathrm{ng} / \mathrm{ml}$; for ages 60-70 years ( $n=19)$ : 1900,2980 and $4680 \mathrm{ng} / \mathrm{ml}$ respectively. IGFBP-1 was assessed by enzyme immunoassay (Mediagnost) with intra- and interassay coefficients of variation of less than $4 \%$ and $8 \%$. IGFBP-4 and IGFBP-5 were measured by specific RIAs with intra- and interassay coefficients of variation of less than $10 \%$, as previously described (Mohan et al. 1995a, Honda et al. 1996). These studies revealed an increase in mean IGFBP-4 serum levels (healthy adults: aged 23-40 years $(n=24): 404 \pm 146$ (S.D.) $\mathrm{ng} / \mathrm{ml}$; aged $41-60$ years $(n=37)$ : $447 \pm 87 \mathrm{ng} / \mathrm{ml}$; aged $61-87$ years $(n=41): 546 \pm 135 \mathrm{ng} /$ $\mathrm{ml})$, and a decrease in mean IGFBP-5 serum levels (healthy prepubertal girls: aged $12 \pm 1 \cdot 3$ years $(n=20)$ : 
Table 2 Serum levels of IGF-I and IGFBPs (mean values \pm S.E.M.) in Type 1, Type 2 and control subjects (100 age- and sex-matched healthy blood donors, mean age: $57 \pm 2 \cdot 6$ years; female/male: $49 / 51$ )

\begin{tabular}{|c|c|c|c|c|}
\hline & $\begin{array}{l}\text { Controls } \\
(n=49 \mathrm{~F} / 51 \mathrm{M})\end{array}$ & $\begin{array}{l}\text { Type } 1 \\
(n=12 \mathrm{~F} / 15 \mathrm{M})\end{array}$ & $\begin{array}{l}\text { Type } 2 \\
(n=13 \mathrm{~F} / 12 \mathrm{M})\end{array}$ & $\begin{array}{l}\boldsymbol{P} \\
\text { (ANOVA) }\end{array}$ \\
\hline \multicolumn{5}{|l|}{ Females } \\
\hline IGF-I & $167 \pm 6$ & $116 \pm 12^{\S}$ & $159 \pm 15$ & * \\
\hline IGFBP-1 & $3 \cdot 6 \pm 0 \cdot 4$ & $47 \pm 11^{\S \S+}$ & $13 \pm 5^{\#}$ & ** \\
\hline IGFBP-3 & $4700 \pm 257$ & $2728 \pm 171^{\S \S+}$ & $3038 \pm 135^{\# \#}$ & ** \\
\hline IGFBP-4 & $379 \pm 17$ & $373 \pm 46$ & $368 \pm 30$ & \\
\hline IGFBP-5 & $445 \pm 11$ & $231 \pm 12^{\S \S}$ & $264 \pm 12^{\# \#}$ & ** \\
\hline \multicolumn{5}{|l|}{ Males } \\
\hline IGF-I & $170 \pm 6$ & $122 \pm 10^{\S+}$ & $187 \pm 21$ & * \\
\hline IGFBP-1 & $3 \cdot 2 \pm 0 \cdot 3$ & $31 \pm 14^{\S \S+}$ & $10 \pm 3^{\#}$ & ** \\
\hline IGFBP-3 & $4560 \pm 227$ & $2474 \pm 108^{\S \S}$ & $2664 \pm 167^{\# \#}$ & $* *$ \\
\hline IGFBP-4 & $370 \pm 18$ & $324 \pm 27$ & $340 \pm 29$ & \\
\hline IGFBP-5 & $477 \pm 8$ & $241 \pm 13^{\S \S}$ & $219 \pm 14^{\# \#}$ & ** \\
\hline
\end{tabular}

ANOVA: Type 1 vs Type 2 vs Control: ${ }^{*}=P<0 \cdot 05,{ }^{* *}=P<0 \cdot 005$; Newman-Keuls test: Type 1 vs Control; $\S=P<0 \cdot 05$, $\S \S=P<0 \cdot 005$; Type 2 vs Control: $\#=P<0 \cdot 05, \# \#=P<0 \cdot 005$; Type 1 vs Type $2:+=P<0 \cdot 05 . \mathrm{M}$, male; $\mathrm{F}$, female.

$664 \pm 109 \mathrm{ng} / \mathrm{ml}$; healthy adult women: aged $51 \pm 31$ years $(n=30): 417 \pm 194 \mathrm{ng} / \mathrm{ml})$.

Serum insulin was measured by a specific enzyme immunoassay (DRG Instruments, Marburg, Germany) which did not cross-react with proinsulin. In Type 2 subjects, serum proinsulin and C-peptide were determined as markers of residual $\beta$-cell function in Type 2 diabetes by specific enzyme immunoassays (DRG Instruments). All three assays showed intra- and interassay coefficients of variation of less than $8 \%$ and $10 \%$.

\section{Measurement of BMD}

To measure BMD we chose dual-energy X-ray absorptiometry (DEXA; HOLOGIC QDR 1000; Siemens Medical Systems, Erlangen, Germany) for its high precision $(0 \cdot 2 \%-$ $2 \%)$, its high accuracy $(3 \%-5 \%)$, its low radiation hazard with an absorbed dose of radiation of $10-30 \mu \mathrm{Sv}$, and its short examination time of about $10 \mathrm{~min}$ (Kellie 1992). BMD was measured at hip (femoral neck, Ward's triangle, trochanter region) and lumbar spine $\left(\mathrm{L}_{1}-\mathrm{L}_{4}\right)$ in anteriorposterior projection. All measurements were corrected for superimposition artifacts. The BMD of each patient was calculated as the percentage of the mean value (Z-score \%) obtained from a healthy control group matched for sex and age (HOLOGIC database).

\section{Statistical analyses}

Data are presented as individual values or as means \pm S.E.M. except where otherwise indicated. Differences between the experimental groups were determined by performing a one-way analysis of variance (ANOVA), followed by Newman-Keuls test. The analysis was separated for additional parameters (e.g. sex). Correlations between variables were assessed using univariate linear regression analysis. Partial correlation analysis was used to predict the correlations between IGF system components and BMD after correction for age, BMI and diabetes duration. $P<0 \cdot 05$ was accepted as statistically significant.

\section{Results}

\section{Clinical data and serum parameters}

The clinical data and the serum parameters are given in Table 1. Type 1 patients were of younger age but showed a longer duration of the disease compared with the Type 2 group. All subjects showed normal serum values for creatinine, calcium, phosphate, PTH, 25- $\mathrm{OHD}_{3}, 1,25-$ $(\mathrm{OH})_{2} \mathrm{D}_{3}$ and biochemical markers of bone turnover. Male Type 2 diabetics showed the highest PTH levels and a significantly lower ratio of PICP (indicating bone formation) to ICTP (a marker of bone loss).

\section{IGF-I and IGFBP serum levels and interrelations}

Type 1 patients revealed significantly lower IGF-I and IGFBP-3 but higher IGFBP-1 serum levels than Type 2 or control subjects (Table 2). IGF-I correlated negatively with IGFBP-1 (Type 1: $r=-0 \cdot 57, P<0 \cdot 01$; Type 2: $r=-0 \cdot 37, P<0 \cdot 05$ ) and IGFBP-4 (Type 1: $r=-0 \cdot 38$, $P<0 \cdot 05$; Type 2: $r=-0 \cdot 14$, n.s.) but positively with IGFBP-3 (Type 1: $r=0 \cdot 56, P<0 \cdot 01$; Type 2: $r=0 \cdot 65$, $P<0 \cdot 01$ ) and IGFBP-5 (Type 1: $r=0 \cdot 76, P<0 \cdot 005$; Type 2: $r=0 \cdot 39, P<0 \cdot 05)$. Figure 1 demonstrates these correlations for both diabetic groups. In the healthy control subjects, similar correlations between IGF-I and the IGFBPs were observed (female/male): IGF-I vs IGFBP-1 $(r=-0 \cdot 43 /-0 \cdot 42, P<0 \cdot 01)$, IGF-I vs IGFBP-3 $(r=0 \cdot 47 /$ $0 \cdot 49, P<0 \cdot 005)$, IGF-I vs IGFBP-4 $(r=-0 \cdot 21 /-0 \cdot 22$, 

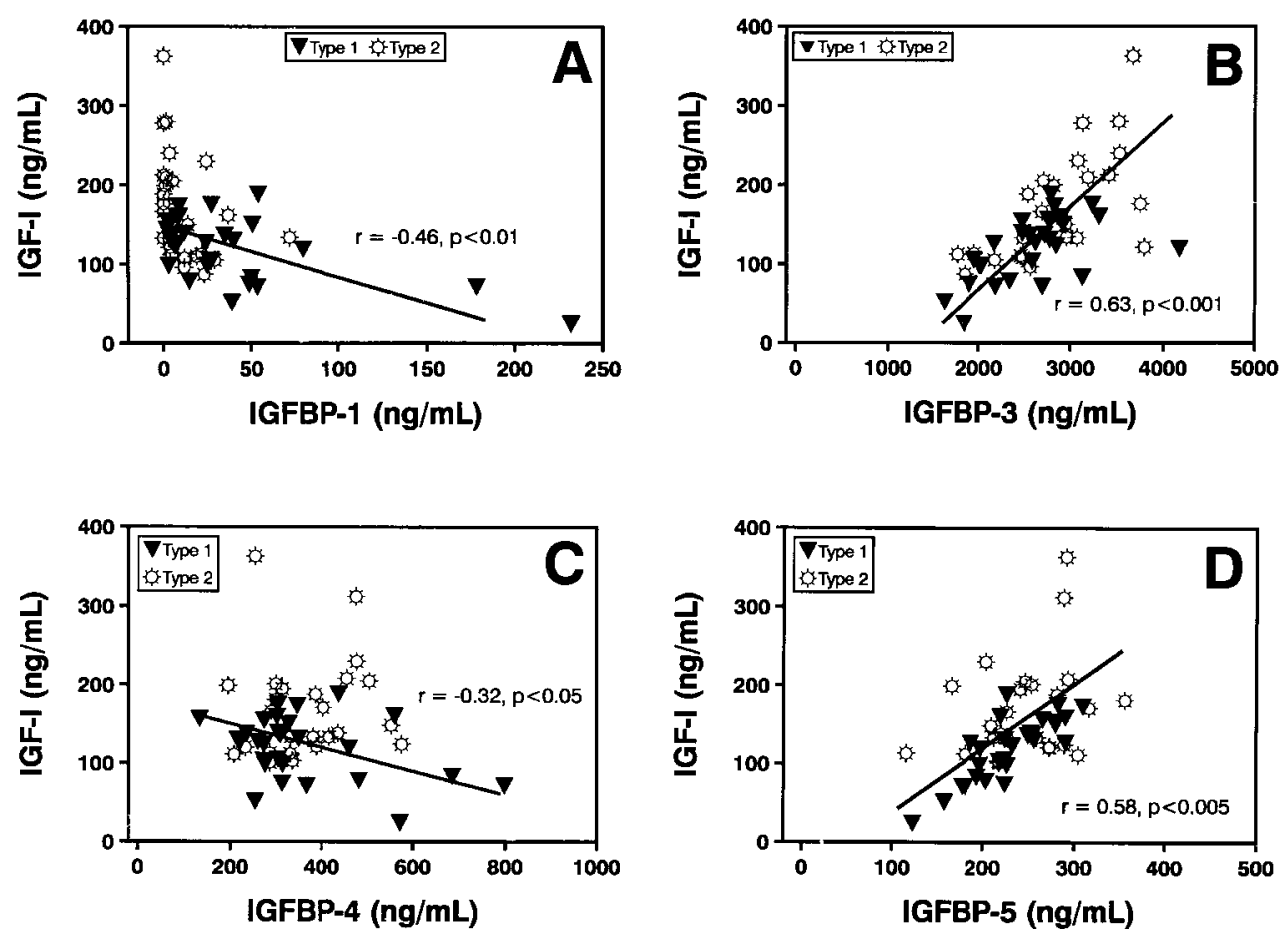

Figure 1 Relationship between IGF-I and IGFBPs in 52 diabetic patients. IGF-I correlated negatively with (A) IGFBP-1 and (C) IGFBP-4 and positively with (B) IGFBP-3 and (D) IGFBP-5.

$P<0 \cdot 05)$ and IGF-I vs IGFBP-5 $(r=0 \cdot 21 / 0 \cdot 41, P<0 \cdot 05 /$ $0 \cdot 01)$.

\section{Relationship of IGF-I and IGFBPs to age and diabetes duration}

Diabetes duration showed strong negative correlations with IGF-I (Type 1: $r=-0 \cdot 64, P<0 \cdot 005$ ), IGFBP-3 (Type $1 / 2: r=-0 \cdot 44 /-0 \cdot 38, P<0 \cdot 05)$ and IGFBP-5 (Type 1: $r=-0 \cdot 6, P<0 \cdot 005)$. Similar correlations were obtained with age, which was further positively correlated with IGFBP-1 (Type 1/2: $r=0 \cdot 39 / 0 \cdot 32, P<0 \cdot 05$ ). The correlations between IGF-I and IGFBPs (Fig. 1) were still significant after correction for the variables age, diabetes duration, height, weight and BMI by partial correlation analysis.

$B M D$ and relationship to IGF system, bone metabolism and clinical data

The BMDs of hip (Fig. 2A) and lumbar spine (Fig. 2B) were lower in Type 1 than in Type 2 patients, reaching statistical significance in female subjects. Male Type 2 diabetics showed a lower BMD of lumbar spine than females $(P<0 \cdot 005)$. BMD of hip correlated positively with BMD of lumbar spine (Type 1: $r=0 \cdot 41, P<0 \cdot 05$; Type 2 : $r=0.76, P<0 \cdot 001)$. In Type 1 patients, BMD of hip correlated negatively with IGFBP-1 (Fig. 3A) and IGFBP-4 (Fig. 3B), and positively with IGFBP-5 (Fig. 3C). Furthermore, BMD of hip correlated positively with $1,25-(\mathrm{OH})_{2} \mathrm{D}_{3} \quad(r=0 \cdot 56, \quad P<0 \cdot 01)$ and negatively with microalbumin in urine $(r=-0 \cdot 46, P<0 \cdot 05)$, serum levels of PTH $(r=-0.33, P<0.05)$ and the bone resorption marker ICTP $(r=-0 \cdot 31, P<0 \cdot 05)$. On the other hand, in Type 2 patients, IGFBP-3 was positively correlated with BMD of hip $(r=0 \cdot 38, P<0 \cdot 05)$ and lumbar spine $(r=0 \cdot 45$, $P<0 \cdot 05)$. In all subgroups, there was a significant positive relationship between BMD and BMI. The group with the highest BMI, female Type 2 patients, also showed the strongest correlation (BMI vs BMD of hip: $r=0.59$; and lumbar spine: $r=0 \cdot 49, P<0 \cdot 05)$. In contrast, female Type 1 patients not only showed the lowest BMD, lower levels of IGF-I, IGFBP-3 and IGFBP-5 and higher levels of IGFBP-1 and IGFBP-4, but also the lowest BMI and the longest diabetes duration (Table 1). Therefore, we performed partial correlation analysis to further assess whether circulating IGF system components contribute independently of age, diabetes duration, height, weight and BMI to BMD in both types of diabetes mellitus. In Type 1 subjects, BMD of hip still correlated negatively with IGFBP-4 $(r=-0.33, \quad P<0 \cdot 05)$ and positively with IGFBP-5 $(r=0 \cdot 57, P<0 \cdot 01)$, while in Type 2 patients the positive relationship between IGFBP-3 and BMD of hip or lumbar spine lost its statistical significance $(r=0 \cdot 21$ and $0 \cdot 23$ respectively). 

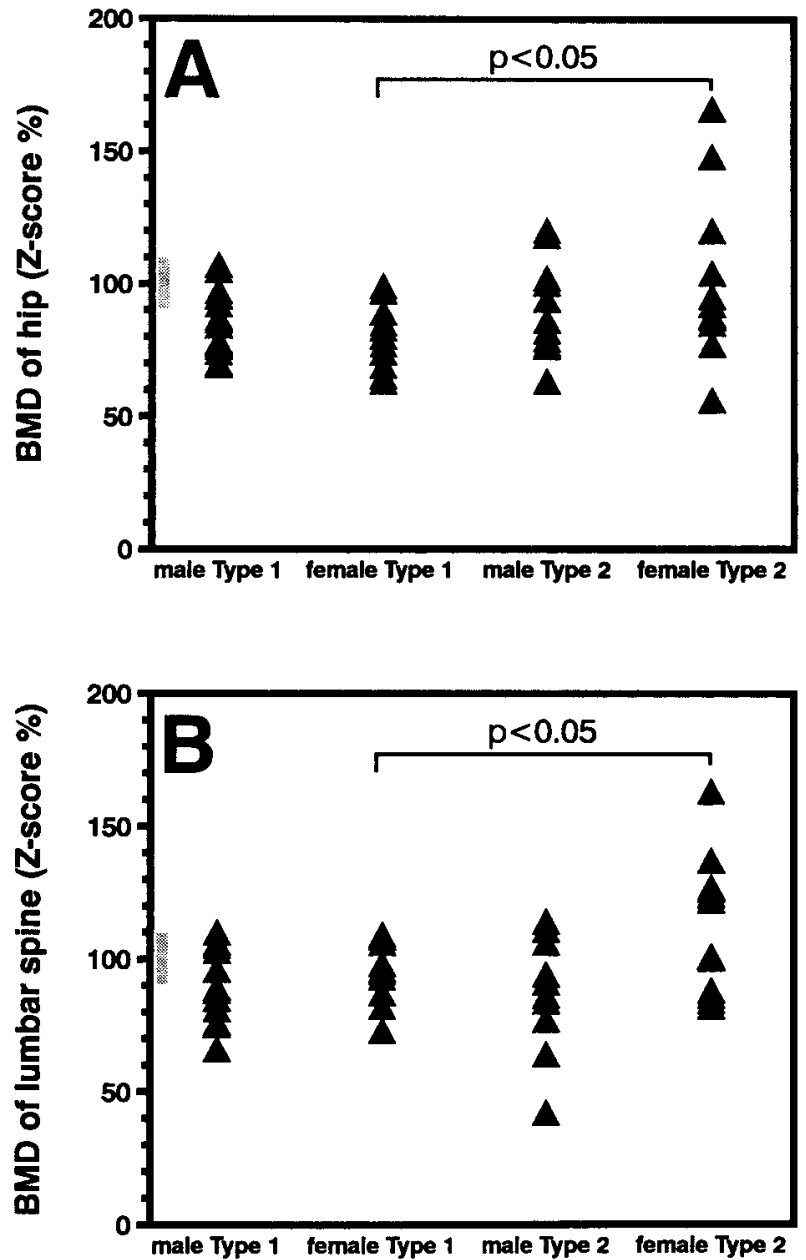

Figure 2 BMD (Z-score \%) measured at (A) hip and (B) lumbar spine in 27 Type 1 and 25 Type 2 diabetes patients. The reference values of age- and sex-matched healthy controls were obtained from the HOLOGIC database and are defined as 100\% (shaded bar=1 S.D.).

Relationship between IGF system components, markers of bone metabolism and diabetes therapy

In Type 1 patients, IGF-I correlated positively with the bone formation marker B-ALP $(r=0 \cdot 33, P<0 \cdot 05)$ and showed a negative correlation with ICTP $(r=-0 \cdot 42$, $P<0 \cdot 05)$, an acknowledged marker of bone loss. IGFBP-1 showed strong positive correlations with ICTP $(r=0 \cdot 8$, $P<0 \cdot 001)$ and OSC $(r=0 \cdot 64, P<0 \cdot 005)$, IGFBP-3 correlated positively with the bone formation marker PICP $(r=0 \cdot 3, P<0 \cdot 05)$, and IGFBP-4 showed significant positive correlations with both ICTP $(r=0 \cdot 42, P<0 \cdot 05)$ and PTH $(r=0.68, \quad P<0 \cdot 005)$, whereas the opposite was found with IGFBP-5 $(r=-0.5$ and -0.31 respectively, $P<0 \cdot 05)$. Among the vitamin $\mathrm{D}_{3}$ metabolites, $25-\mathrm{OHD}_{3}$ correlated positively with IGFBP-3 $(r=0 \cdot 51, P<0 \cdot 05)$ and $1,25-(\mathrm{OH})_{2} \mathrm{D}_{3}$ with IGFBP-5 $(r=0 \cdot 34, P<0 \cdot 05)$. The
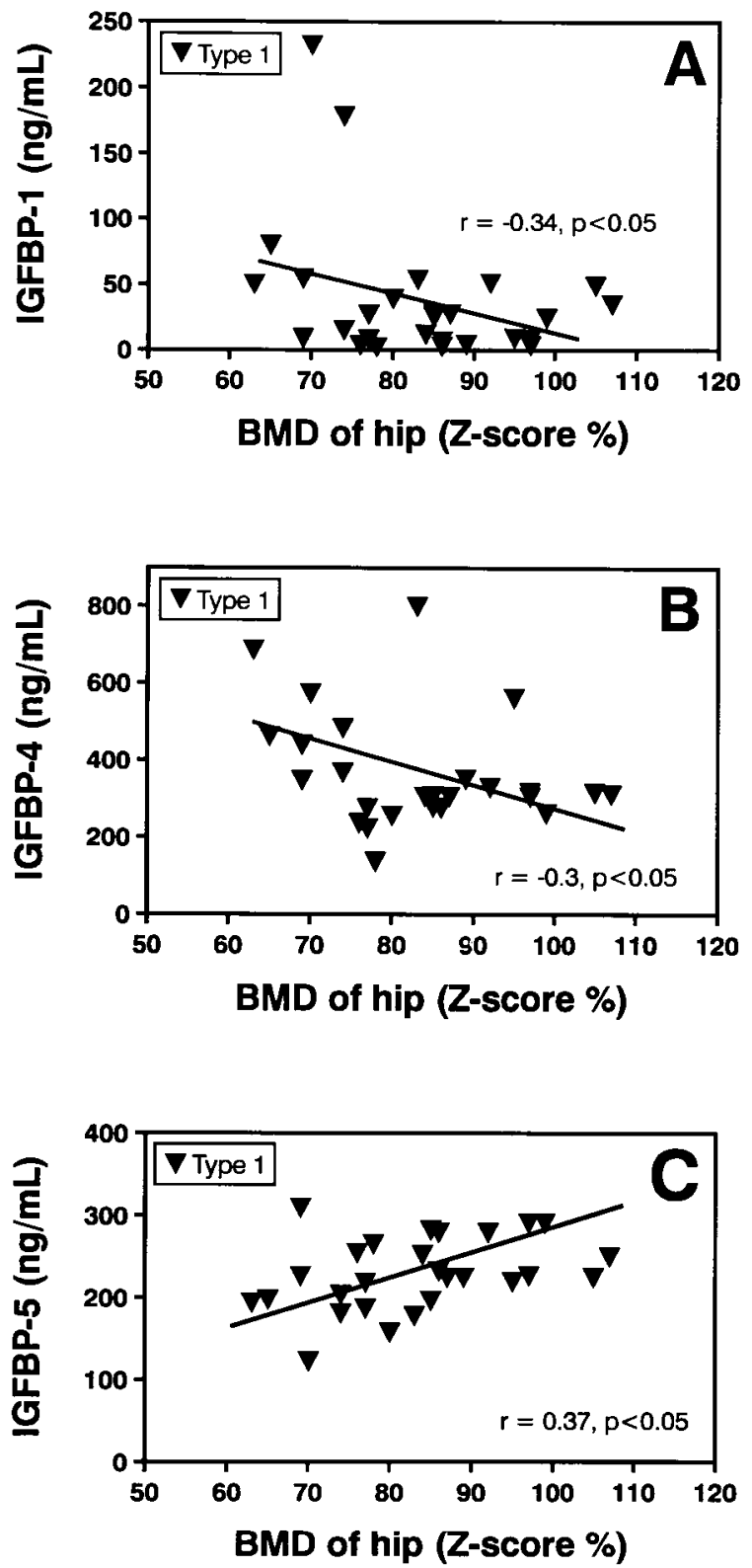

Figure 3 Relationship between BMD of hip and IGFBPs in Type 1 patients. BMD of hip correlated negatively with (A) IGFBP-1 and (B) IGFBP-4 and positively with (C) IGFBP-5.

dose of injected insulin correlated positively with IGF-I $(r=0.37, \quad P<0.05)$ and B-ALP $(r=0.31, \quad P<0.05)$ but negatively with OSC $(r=-0 \cdot 30, P<0 \cdot 05)$ and ICTP $(r=-0 \cdot 36, P<0 \cdot 05)$. In Type 2 diabetics, there was a positive relationship between ICTP and PICP $(r=0 \cdot 45$, $P<0 \cdot 05)$ which was not observed in Type 1 diabetics, indicating that the increased rate of bone resorption was not associated with a compensatory increase in the rate of bone formation in the latter group (i.e. negative 
Table 3 BMD, IGF system components and 1,25-(OH $)_{2} \mathrm{D}_{3}$ levels (mean values \pm S.E.M.) in diabetic subjects without microalbuminuria $(-$ microA), with microalbuminuria (+microA; incipient diabetic nephropathy) and with macroalbuminuria (+macroA; manifest diabetic nephropathy)

\begin{tabular}{|c|c|c|c|c|}
\hline & $\begin{array}{l}- \text { microA } \\
(n=37(22 / 15))^{\dagger}\end{array}$ & $\begin{array}{l}\text { +microA } \\
(n=10(2 / 8))^{\dagger}\end{array}$ & $\begin{array}{l}\text { +macroA } \\
(n=5(2 / 3))^{\dagger}\end{array}$ & $\begin{array}{l}\boldsymbol{P} \\
(\mathrm{ANOVA})\end{array}$ \\
\hline BMD of hip (Z-score \%) & $90 \pm 3$ & $88 \pm 9$ & $82 \pm 12$ & \\
\hline IGFBP-4 (ng/ml) & $341 \pm 183$ & $332 \pm 108$ & $532 \pm 19^{\S \#}$ & * \\
\hline IGFBP-5 (ng/ml) & $239 \pm 51$ & $223 \pm 62$ & $210 \pm 25$ & \\
\hline IGFBP-5 vs IGFBP-4 & $0 \cdot 7$ & 0.67 & $0 \cdot 39^{\S \#}$ & * \\
\hline $1,25-(\mathrm{OH})_{2} \mathrm{D}_{3}(\mathrm{pg} / \mathrm{ml})$ & $52 \pm 17$ & $57 \pm 15$ & $28 \pm 5^{\S \#}$ & * \\
\hline
\end{tabular}

ANOVA: $(-$ microA vs + microA vs + macroA $):{ }^{*}=P<0 \cdot 05$, Newman-Keuls test: $(-$ microA vs + macroA $): \S=P<0 \cdot 05,(+$ microA vs + macroA): $\#=P<0 \cdot 05 .{ }^{\dagger}$ Number of subjects in each group (Type 1/Type 2 ).

uncoupling of bone formation to resorption). In the insulin-treated Type 2 patients, the dose of injected insulin revealed significant negative correlations with IGFBP-4 $(r=-0 \cdot 44, P<0 \cdot 05)$, OSC $(r=-0 \cdot 35, P<0 \cdot 05)$ and ICTP $(r=-0 \cdot 34, P<0 \cdot 05)$.

\section{Relationship between residual $\beta$-cell function, IGF system and $B M D$ in Type 2 diabetes}

In 20 Type 2 subjects (female/male: 11/9) proinsulin $(85 \pm 22 / 50 \pm 16 \mathrm{pg} / \mathrm{ml})$ and C-peptide $(2 \cdot 2 \pm 0 \cdot 5 /$ $2 \cdot 8 \pm 0 \cdot 7 \mathrm{ng} / \mathrm{ml}$ ) could be detected in serum. In these patients, proinsulin levels showed stronger positive correlations with BMD of hip $(r=0.63, P<0.005)$ and lumbar spine $(r=0 \cdot 58, P<0 \cdot 005)$ than $\mathrm{C}$-peptide, whereas insulin levels did not correlate. Furthermore, proinsulin showed significant positive correlations with IGF-I $(r=0.59$, $P<0 \cdot 01)$ IGFBP-3 $(r=0 \cdot 49, P<0 \cdot 05)$ and BMI $(r=0 \cdot 35$, $P<0 \cdot 05)$.

\section{Relationship of renal function to IGF system and bone metabolism}

Serum creatinine levels correlated positively with age (Type 1: $r=0 \cdot 44, P<0 \cdot 05$ ), IGFBP-1 (Type 1: $r=0 \cdot 52$, $P<0 \cdot 05$ ), IGFBP-4 (Type 1/2: $r=0 \cdot 64 / 0 \cdot 5, \quad P<0 \cdot 005 /$ $0 \cdot 05)$ and markers indicating bone loss such as ICTP (Type 1/2: $r=0 \cdot 72 / 0 \cdot 65, P<0 \cdot 005$ ), or bone turnover such as OSC (Type 1: $r=0 \cdot 71, P<0 \cdot 005$ ) and PTH (Type 1: $r=0 \cdot 61, P<0 \cdot 005)$. On the other hand, serum creatinine correlated negatively with IGF-I (Type 1: $r=-0 \cdot 45$, $P<0 \cdot 05), \quad$ IGFBP-5 (Type 1/2: $\quad r=-0 \cdot 38 /-0 \cdot 31$, $P<0 \cdot 05)$ and 1,25-(OH $)_{2} \mathrm{D}_{3}$ (Type 2: $r=-0 \cdot 8, P<0 \cdot 001$ ). The excretion of albumin in urine, an acknowledged marker of diabetic nephropathy, was measured within the normal range $(<20 \mu \mathrm{g} / \mathrm{min})$ in 37 patients. In 10 patients microalbuminuria was observed $(117 \pm 9 \mu \mathrm{g} / \mathrm{min})$, while 5 patients showed macroalbuminuria $(1309 \pm 330 \mu \mathrm{g} /$ $\mathrm{min})$, indicating manifest diabetic nephropathy. Linear regression analysis showed that the excretion of albumin in urine correlated positively with IGFBP-4 (Type 1/2: $r=0 \cdot 47 / 0 \cdot 37, P<0 \cdot 05)$ and negatively with the BMD of hip (Type 1: $r=-0 \cdot 46, P<0 \cdot 05)$. As demonstrated in Table 3, the macroalbuminuric patients showed a lower BMD of hip, a lower molar ratio of IGFBP-5 vs IGFBP-4 and lower $1,25-(\mathrm{OH})_{2} \mathrm{D}_{3}$ levels.

\section{Discussion}

The current study provides the first analysis of immunoreactive serum levels of IGF-I, IGFBPs-1, $-3,-4$ and -5 and proinsulin together with biochemical markers of bone metabolism, BMD and renal function in a group of Type 1 and Type 2 diabetic patients. Type 1 diabetics showed markedly lower IGF-I and higher IGFBP-1 levels compared with Type 2 patients and control subjects, consistent with several previous reports (Crosby et al. 1992, Dills et al. 1995, Hilding et al. 1995, Strasser-Vogel et al. 1995). Compared with published normal ranges for the assays, IGF-I levels in Type 1 diabetics were below the 20th percentile. IGFBP-3 levels were below the 50 th percentile in Type 1 patients and in male Type 2 patients. The imbalance in circulating IGF-I, IGFBP-1 and IGFBP-3 levels appeared to be characteristic of insulin-deficient Type 1 diabetics rather than of Type 2 subjects with residual $\beta$-cell function. This is pathophysiologically plausible since insulin inhibits IGFBP-1 production but stimulates the synthesis of IGF-I (Bereket et al. 1995) and both IGFBP-1 and glucose are significant predictors for the levels of IGF-I (Hong et al. 1997). In line with these reports, we observed a negative relationship between diabetes duration and serum levels of IGF-I and IGFBP-3, as well as a positive correlation between serum IGF-I and the amount of injected insulin in Type 1 diabetics. IGFBP-3 levels were below the 50th percentile in Type 1 patients and in male Type 2 patients. For the first time, our study demonstrated that IGFBP-5 serum levels are substantially lower in both types of diabetes mellitus patient than in age- and sex-matched healthy controls. Like IGF-I and IGFBP-3, IGFBP-5 levels decrease with age (Mohan et al. 1995a). Thus, higher IGFBP-5 levels should be expected in the younger Type 1 diabetics. However, the strong negative relationship between 
diabetes duration and IGFBP-5 suggests that diabetes plays an important role. In all subjects studied, serum IGF-I showed negative correlations with IGFBP-1 and positive correlations with IGFBP-3, which is in good accordance with previous reports (Argente et al. 1993, Blum \& Breier 1994, Hilding et al. 1995). Our data further show that IGF-I correlated negatively with IGFBP-4 but positively with IGFBP-5. Taken together, this supports the concept that IGFBPs may predominantly stimulate (e.g. IGFBP-3, IGFBP-5) or inhibit (e.g. IGFBP-1, IGFBP-4) IGF action; however, the same IGFBP may exert stimulatory and inhibitory effects depending on the tissue type or the local conditions (Mohan et al. 1989, Jones \& Clemmons 1995, Mohan et al. 1995a,b, Rajaram et al. 1997).

The finding that BMD is lower in Type 1 compared with Type 2 patients is in accordance with several other reports (Levin et al. 1976, McNair et al. 1978, Krakauer et al. 1995, Van Daele et al. 1995). We further observed a lower BMD of lumbar spine in male than in female Type 2 diabetics. The higher PTH levels and the lower ratio of PICP to ICTP may indicate a mild secondary hyperparathyroidism which is typically found in the early stages of declining renal function (vide infra). Considering the positive relationship between BMD and BMI, it is likely that the nutritional status may contribute considerably to bone formation. Several studies indicated that protein intake is especially closely related to the IGF system and osteoporosis (Bonjour et al. 1997). Furthermore, it is important to address how alterations in circulating IGFBPs may influence the bioavailability of IGFs for target tissues such as bone. Since the modulation of IGF action is rather complex (Rajaram et al. 1997), the key question beyond the present study is whether individual IGF system components may contribute to bone loss (Rosen et al. 1994). Although our cross-sectional study cannot prove etiological relationships, our data suggest an association between circulating IGF system components and bone metabolism. The significant correlations between circulating IGF system components and BMD in Type 1 diabetics persisted after statistical correction for the variables BMI, age and diabetes duration. Similar to our results, decreased serum levels of IGF-I and IGFBP-3 and significant positive correlations between these IGF system components and BMD have been reported in patients with osteoporosis (Wüster et al. 1993). Another study demonstrated that serum levels of IGF-I showed a significant positive correlation with the osteoblastic surface measured by histomorphometric techniques (Reed et al. 1995). The role of circulating IGF-I in stimulating bone growth and metabolism is clearly supported by studies showing that (1) the restoration of the markedly reduced serum IGF-I levels by injection of recombinant human (rh)IGF-I dramatically stimulates longitudinal growth in patients with Laron syndrome (growth hormone $(\mathrm{GH})$ receptor defect; Laron \& Klinger 1994), and (2) the subcutaneous application of rhIGF-I stimulated bone turnover in healthy young adults
(Mauras et al. 1996) as well as in postmenopausal women (Eberling et al. 1993). Consistent with the anabolic role of IGF-I in bone (Mohan 1993, Narusawa et al. 1995, Reed et al. 1995, Ono et al. 1996), we suggest that in Type 1 patients the lower IGF-I levels may contribute to diminished stimulation of bone formation, leading to a fall in BMD with time. In this context it should be considered that not only IGF-I but also IGFBPs may directly act on bone cells. In vitro studies have shown that IGFBP-4 is a potent inhibitor of IGF actions on bone cells by preventing the IGFs from binding to their receptors (Mohan et al. 1989). On the other hand, IGFBP-5 may exert anabolic effects on osteoblasts by an IGF-independent mechanism involving IGFBP-5-specific binding sites (Mohan et al. 1995b). For the first time, our study has demonstrated that BMD of hip correlates negatively with circulating IGFBP-4 and positively with IGFBP-5 in Type 1 diabetics. Although the exact functional role of serum IGFBP-4 and IGFBP-5 is not clear at this time, increased IGFBP4 serum levels have been previously reported in patients with elevated serum PTH levels and hip fractures (Rosen et al. 1992). Further studies are needed to determine whether the measurement of circulating IGF system components can be used as a suitable tool for the diagnosis and therapeutic monitoring of osteopenia and osteoporosis in Type 1 diabetes.

The finding that OSC and B-ALP are in the low normal range in both diabetic groups indicates an impaired bone turnover and formation which has been previously reported in both types of diabetes mellitus (Bouillon et al. 1995, Krakauer et al. 1995). In a recent study, it has been demonstrated that $\mathrm{GH}$ treatment of $\mathrm{GH}$-deficient children increases serum levels of IGF-I, IGFBP-3, IGFBP-5 and B-ALP (Ono et al. 1996). Consistent with these data, we observed that IGF-I, IGFBP-3 and IGFBP-5 showed positive correlations with B-ALP, an acknowledged marker of bone formation, and also with $25-\mathrm{OHD}_{3}$ and $1,25-(\mathrm{OH})_{2} \mathrm{D}_{3}$. In contrast, IGFBP-1 and IGFBP4 showed positive correlations with PTH and with ICTP, a marker of bone resorption, as well as with OSC, a marker of bone turnover (Power \& Fottrell 1991). The finding that the age of Type 1 patients revealed a stronger direct correlation with ICTP than with PICP supports the well-established concept that bone resorption increases but matrix formation decreases with age (Parfitt et al. 1983, Eriksen et al. 1993, Bouillon et al. 1995). In contrast to Type 2 patients, in Type 1 there was no significant positive correlation between ICTP and PICP, indicating that the increased rate of bone resorption was not associated with a compensatory increase in the rate of bone formation (i.e. negative uncoupling of bone formation to resorption).

For the first time, our study also suggests a role for proinsulin in the regulation of bone formation in Type 2 diabetics. Earlier reports in Type 2 diabetes described a relationship between obesity and elevated proinsulin levels 
(Nagi et al. 1990), and positive correlations between urinary C-peptide, BMD and BMI (Wakasugi et al. 1993). We observed that proinsulin not only showed stronger positive correlations with BMD than C-peptide, but that it also correlated positively with IGF-I and IGFBP-3. Thus, it can be speculated that, in Type 2 diabetics, residual proinsulin secretion may protect from bone loss. Whether proinsulin may stimulate bone formation via the IGF system, a changed nutritional status or by an independent mechanism (e.g. via specific receptors; Jehle et al. 1996) remains to be investigated.

Although all subjects showed normal serum creatinine levels, even early diabetic nephropathy may contribute to bone loss. In Type 1 patients, we observed a significant negative correlation between the extent of microalbuminuria and BMD of hip. In the Type 2 group, the male subjects showed significantly higher levels of urinary microalbumin and a lower BMD of hip and lumbar spine compared with females. Compared with patients with microalbuminuria, diabetic patients with macroalbuminuria showed a lower ratio of IGFBP-5 to IGFBP-4, which was mainly due to elevated IGFBP-4 levels. Thus, we conclude that diabetic nephropathy further disturbs the balance between circulating IGF system components and thereby may act as a co-factor for the development of osteopenia in diabetes mellitus.

In summary, patients with Type 1 diabetes showed a lower bone mass, lower IGF-I serum levels and alterations in the pattern of IGFBPs compared with Type 2 diabetics and controls. In Type 2 diabetics, pancreatic proinsulin secretion and obesity may protect from bone loss, possibly via the IGF system.

\section{Acknowledgements}

The authors wish to thank Thomas Pfeifer for the evaluation of BMD measurements, Dietmar Zellner for performing the partial correlation analysis, and Rosa Herzog, Antje Ostertag, Sabine Ott and Dr Sylvia Stracke for performing the RIAs. This work was supported by the Landesforschungsschwerpunkte Baden-Württemberg: 'Wachstumsfaktor-Modulation als therapeutisches Prinzip', 'Ursachen, Folgen und neue Therapieformen des Insulinmangels' and an NIH grant (AR31062).

\section{References}

Argente J, Barrios V, Pozo J, Munoz MT, Hervas MT, Stene M \& Hernandez M 1993 Normative data for insulin-like growth factors (IGFs), IGF-binding proteins, and growth hormone-binding protein in a healthy Spanish pediatric population: age- and sex-related changes. Journal of Clinical Endocrinology and Metabolism 77 1522-1528.

Bang P, Baxter RC, Blum WF, Breier BH, Clemmons DR, Hall K, Hintz RL, Holly JM, Rosenfeld RG \& Zapf J 1994 Valid measurements of total IGF concentrations in biological fluids. Recommendations from the 3rd International Symposium on Insulin-like Growth Factors. Journal of Endocrinology 143 C1-C2.

Bereket A, Lang CH, Blethen SL, Gelato MC, Fan J, Frost RA \& Wilson TA 1995 Effects of insulin on the insulin-like growth factor system in children with new-onset insulin-dependent diabetes mellitus. Journal of Clinical Endocrinology and Metabolism $\mathbf{8 0}$ 1312-1317.

Blum WF \& Breier B 1994 Radioimmunoassay for IGFs and IGFBPs. Growth Regulation 4 (Suppl 1) 11-19.

Bonjour JP, Schürch MA, Chevalley T, Ammann P \& Rizzoli R 1997 Protein intake, IGF-1 and osteoporosis. Osteoporosis International 7 (Suppl 3) S36-S42.

Bouillon R, Bex M, Van Herck E, Laureys J, Dooms L, Lesaffre E \& Ravussin E 1995 Influence of age, sex, and insulin on osteoblast function and dysfunction in diabetes mellitus. Journal of Clinical Endocrinology and Metabolism 80 1194-1202.

Crosby SR, Tsigos C, Anderton CD, Gordon Young RJ \& White A 1992 Elevated plasma insulin-like growth factor binding protein-1 levels in type I (insulin-dependent) diabetic patients with peripheral neuropathy. Diabetologia 35 868-872.

Dills DG, Allen C, Palta M, Zaccaro DJ, Klein R \& D'Alessio D 1995 Insulin-like growth factor-I is related to glycemic control in children and adolescents with newly diagnosed insulin-dependent diabetes. Journal of Clinical Endocrinology and Metabolism 80 2139-2143.

Eberling PR, Jones JD, O'Fallon WM, Janes CH \& Riggs BL 1993 Short term effects of rhIGF-1 on bone turnover in normal women. Journal of Clinical Endocrinology and Metabolism 77 1384-1387.

Eriksen EF, Charles P, Melson F, Mosekilde L, Risteli L \& Risteli J 1993 Serum markers of type I collagen formation and degeneration in metabolic bone disease. Correlation to bone histomorphometry. Journal of Bone and Mineral Research 8 127-132.

Hilding A, Brismar K, Degerblad M, Thorén M \& Hall K 1995 Altered relation between circulating levels of insulin-like growth factor-binding protein-1 and insulin in growth hormone-deficient patients and insulin dependent diabetic patients compared with that in healthy subjects. Journal of Clinical Endocrinology and Metabolism $\mathbf{8 0}$ 2646-2652.

Honda Y, Landale EC, Strong DD, Baylink DJ \& Mohan S 1996 Recombinant synthesis of insulin-like growth factor-binding protein-4 (IGFBP-4): development, validation, and application of a radioimmunoassay for IGFBP-4 in human serum and other biological fluids. Journal of Clinical Endocrinology and Metabolism 81 1389-1396.

Hong Y, Brismar K, Hall K, Pedersen NL \& de-Faire U 1997 Associations between insulin-like growth factor-I (IGF-I), IGF-binding protein-1, insulin and other metabolic measures after controlling for genetic influences: results from middle-aged and eldely monozygotic twins. Journal of Endocrinology 153 251-257.

Jehle PM, Lutz MP \& Fussgaenger RD 1996 High affinity binding sites for proinsulin in human IM-9 lymphoblasts. Diabetologia 39 $421-432$.

Jones J \& Clemmons DR 1995 Insulin-like growth factors and their binding proteins: biological actions. Endocrine Reviews 16 3-34.

Kellie SE 1992 Diagnostic and therapeutic technology assessment (DATTA): measurement of bone density with dual-energy X-ray absorptiometry (DEXA). Journal of the American Medical Association $267286-294$.

Krakauer JC, McKenna MJ, Buderer NF, Rao DS, Whitehouse FW \& Parfitt AM 1995 Bone loss and bone turnover in diabetes. Diabetes 44 775-782.

Laron Z \& Klinger B 1994 Laron syndrome: clinical features, molecular pathology and treatment. Hormone Research 42 198-202.

Levin ME, Boisseau VC \& Avioli LV 1976 Effects of diabetes mellitus on bone mass in juvenile and adult-onset diabetes. New England Journal of Medicine 294 241-245. 
McCarthy TL, Centrella M \& Canalis E 1989 Insulin-like growth factor (IGF) and bone. Connective Tissue Research 20 277-282.

McNair P, Madsbad S, Christiansen C, Faber OK, Transbol I \& Binder C 1978 Osteopenia in insulin treated diabetes mellitus. Diabetologia 15 87-90.

Mauras N, Doi SQ \& Shapiro JR 1996 Recombinant human insulin-like growth factor I, recombinant human growth hormone, and sex steroids: effects on markers of bone turnover in humans. Journal of Clinical Endocrinology and Metabolism 81 2222-2226.

Mohan S 1993 Insulin-like growth factor binding proteins in bone cell regulation. Growth Regulation 3 67-70.

Mohan S, Bautista C, Wergedal J \& Baylink DJ 1989 Isolation of an inhibitory insulin-like growth factor (IGF) binding protein from bone cell conditioned medium: a potential local regulator of IGF action. Proceedings of the National Academy of Sciences of the USA $\mathbf{8 6}$ 8338-8342.

Mohan S, Libanati C, Dony C, Lang K, Srinivasan N \& Baylink DJ $1995 a$ Development, validation, and application of a radioimmunoassay for insulin-like growth factor binding protein-5 in human serum and other biological fluids. Journal of Clinical Endocrinology and Metabolism 80 2638-2645.

Mohan S, Nakao Y, Honda Y, Landale E, Leser U, Dony C, Lang K \& Baylink DJ 1995b Studies on the mechanisms by which insulin-like growth factor (IGF) binding protein-4 (IGFBP-4) and IGFBP-5 modulate IGF actions in bone cells. Journal of Biological Chemistry 270 20424-20431.

Nagi DK, Hendra TJ, Ryle AJ, Cooper TM, Temple RC, Clark PMS, Schneider AE, Hales CN \& Yudkin JS 1990 The relationships of concentrations of insulin, intact proinsulin, and 32-33 split proinsulin with cardiovascular risk factors in type II (non-insulin-dependent) diabetic subjects. Diabetologia 33 532-537.

Narusawa K, Nakumara T, Suzuki K, Matsuoka Y, Lee LJ, Tanaka H \& Seino Y 1995 The effects of recombinant human insulin-like growth factor (rhIGF)-1 and rhIGF-1/IGF binding protein-3 administration on rat osteopenia induced by ovariectomy with concomitant bilateral sciatic neurectomy. Journal of Bone and Mineral Research 10 1853-1864

Ono T, Kanzaki S, Seino Y, Baylink DJ \& Mohan S 1996 Growth hormone $(\mathrm{GH})$ treatment of $\mathrm{GH}$-deficient children increases serum levels of insulin-like growth factors (IGFs), IGF-binding protein-3 and -5 , and bone alkaline phosphatase isoenzyme. Journal of Clinical Endocrinology and Metabolism 81 2111-2116.

Parfitt AM, Methews CHE, Villanueva AR, Kleerekoper M, Frame B \& Rao DS 1983 Relationship between surface, volume, and thickness of iliac trabecular bone in aging and in osteoporosis: implications for the microanatomic and cellular mechanisms of bone loss. Journal of Clinical Investigation 72 1396-1409.

Power MJ \& Fottrell PF 1991 Osteocalcin: diagnostic methods and clinical applications. Critical Reviews of Clinical Laboratory Sciences $\mathbf{2 8}$ 287-335.

Rajaram S, Baylink DJ \& Mohan S 1997 Insulin-like growth factorbinding proteins in serum and other biological fluids: regulations and functions. Endocrine Reviews 18 801-831.

Reed BY, Zerwekh JE, Sakhaee K, Breslau NA, Gottschalk F \& Pak CYC 1995 Serum IGF 1 is low and correlated with osteoblastic surface in idiopathic osteoporosis. Journal of Bone and Mineral Research 10 1218-1224.

Rosen C, Donahue LR, Hunter S, Holick M, Kavookjian H, Kirschenbaum A, Mohan S \& Baylink DJ 1992 The 24/25 kD serum insulin-like growth factor binding protein is increased in elderly osteoporotic women. Journal of Clinical Endocrinology and Metabolism 74 24-27.

Rosen CJ, Donahue LR \& Hunter SJ 1994 Insulin-like growth factors and bone: the osteoporosis connection. Proceedings of the Society of Experimental Biology and Medicine 206 83-102.

Strasser-Vogel B, Blum WF, Past R, Kessler U, Hoeflich A, Meiler B \& Kiess W 1995 Insulin-like growth factor (IGF)-I and -II and IGF-binding proteins-1, -2 , and -3 in children and adolescents with diabetes mellitus: correlation with metabolic control and height attainment. Journal of Clinical Endocrinology and Metabolism $\mathbf{8 0}$ 1207-1213.

Van Daele PLA, Stolk RP, Burger H, Algra D, Grobbee DE, Hofman A, Birkenhäger JC \& Pols HAP 1995 Bone density in non-insulin-dependent diabetes mellitus. The Rotterdam Study. Annals of Internal Medicine 122 409-414.

Wakasugi M, Wakao R, Tawata M, Gan N, Koizumi K \& Onaya T 1993 Bone mineral density measured by X-ray absorptiometry in patients with non-insulin-dependent diabetes mellitus. Bone $\mathbf{1 4}$ $29-33$.

Wüster C, Blum WF, Schlemilch S, Ranke MB \& Ziegler R 1993 Decreased serum levels of insulin-like growth factor binding protein 3 in osteoporosis. Journal of Internal Medicine 234 249-255.

Received 30 December 1997

Revised manuscript received 31 March 1998 Accepted 15 June 1998 